\title{
Terrenos compartidos en las obras de Joan Brossa y Chema Madoz
}

\author{
KIKA BENEYTO* \\ Common ground in the works of Joan Brossa and Chema \\ Madoz
}

\begin{abstract}
RESUMEN
A Joan Brossa y Chema Madoz siempre les ha interesado romper con los límites que tradicionalmente imponen sus lenguajes. Debido a este ensanchamiento de fronteras sus obras han entrado en un terreno común que los acerca. Este acercamiento no es una mera especulación, pues ellos mismos, al entender que de alguna manera su trabajo se hermanaba, publicaron juntos un pequeño libro llamado Fotopoemario.
\end{abstract}

\section{PALABRAS CLAVE}

Joan Brossa, Chema Madoz, poema, fotografía, colaboración, signo, objeto.

\begin{abstract}
Poet Joan Brossa and photographer Chema Madoz have always been interested in breaking the limits traditionally imposed by each one's medium. Due to this lowering of barriers their work has entered a common ground which has brought the two closer together. This proximity is not mere speculation. They seem to understand that somehow their work coincides because they coauthored a small book called Fotopoemario
\end{abstract}

\section{KEY WORDS}

Joan Brossa, Chema Madoz, poem, photography, collaboration, sign, object.

SUCCÉS

Un advocat va resultar malferit ahir A la tarda quan li va caure al damunt Un tros de la cornisa del Palau de Justícia.

\section{SUCESO}

Un abogado resultó malherido ayer

Por la tarde cuando le cayó encima Un trozo de la cornisa del Palacio de Justicia. ${ }^{1}$

* Profesora en el Grado de Bellas Artes de la Universidad Nebrija. Madrid.

${ }^{1}$ BROSSA, J. Fotopoemario Madrid. La Fábrica. 2003. Pág. 63-65. (Traducción de Carlos Vitale). 


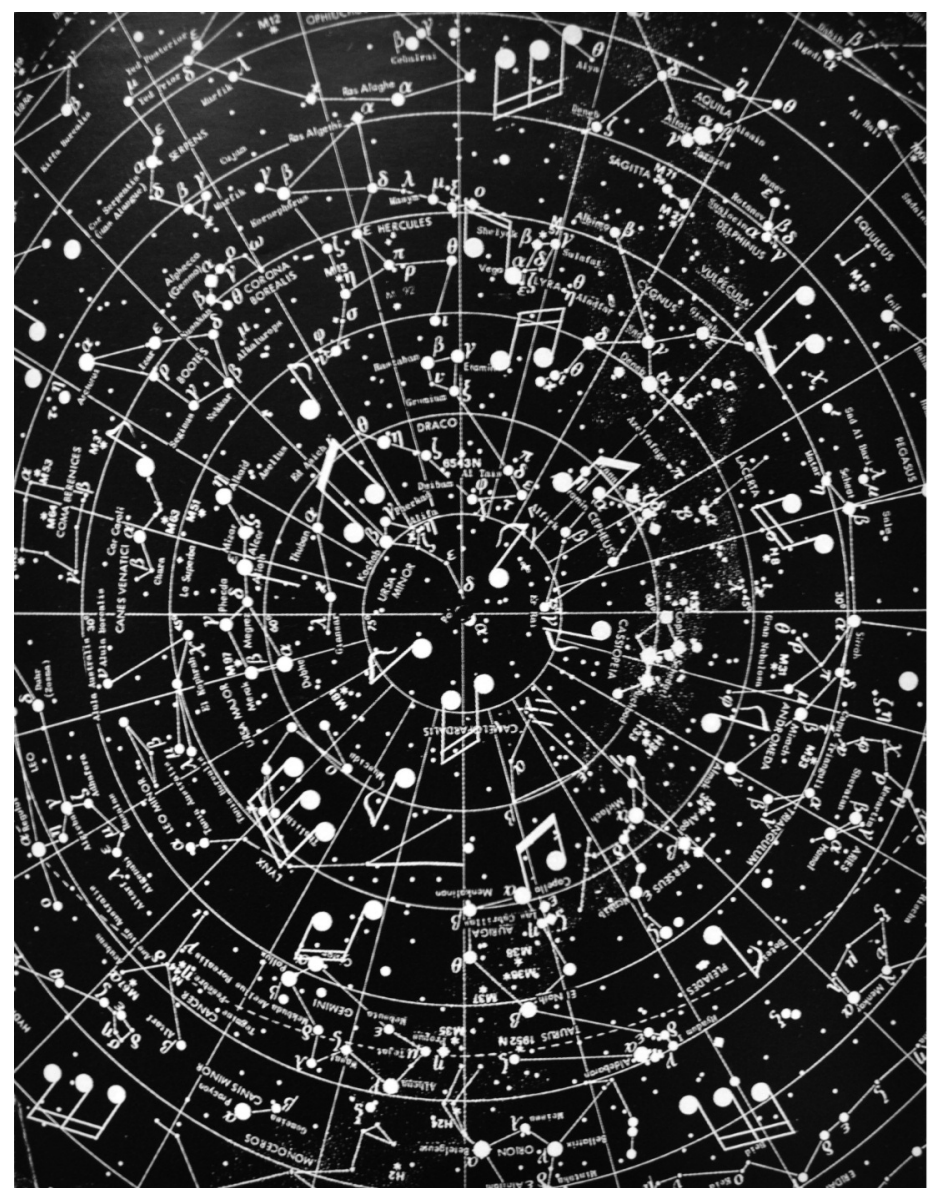

Fig.1. MADOZ. CH.: Fotopoemario. Madrid. La Fábrica. 2003 Pág. 67.

Los nombres de Joan Brossa y Chema Madoz han sido asociados a menudo, aunque Brossa sea poeta y Madoz fotógrafo. Sin embargo, tanto sus obras como ellos mismos se han encontrado en más de una ocasión dado que existen entre ellos inquietudes que comparten. En el caso de Brossa, cuyas primeras obras se centran en la poesía literaria, entendió desde muy pronto que la imagen también puede entrar en el terreno de la poesía, haciendo que el paso de la palabra a la imagen fuera un acto natural. A esta unión él lo llamó «un ensanchamiento de horizontes hacia la libertad „² y bajo esta premisa no sólo se interesó por la poesía, también trabajó la novela, las artes gráficas, el teatro, el cine y la instalación pú-

2 VVAA.: Escrito está. Vitoria. Artium. 2009. pág. 75. 
blica: la libertad para Brossa siempre fue un campo de experimentación donde los límites quedaban muy lejos.

Chema Madoz siempre ha trabajado la fotografía. Sin embargo, ésta es una técnica que se puede utilizar de mil maneras. Madoz parece que ha encontrado en ella una herramienta que lo acerca más al campo de lo poético que al documental. Desde mediados de los años ochenta empieza a trabajar la fotografía fuera de cualquier género clásico, convirtiéndole en un artista inclasificable. No trabaja el retrato, aunque en sus primeras imágenes aparezcan personas. No hace bodegones; nada más alejado de su obra que el término «bodegón». No le interesa el reportaje; entonces ¿qué hace Madoz? Al igual que Brossa, sale de los límites impuestos por las categorizaciones y explora otros terrenos.

Brossa y Madoz pertenecen a generaciones diferentes. Cada uno desde su entorno ha vivido experiencias decisivas en el plano personal, político o artístico. Sin embargo es cierto que hay una similitud en algunos aspectos de sus obras; no sólo en su vertiente más conceptual, donde ambos recurren a la construcción poética, sino también en una vertiente más formal. Pero por otro lado, sus procesos son tan diferentes entre sí, que las posibles similitudes en los resultados no dejan de guardar las características propias de cada uno, recalcando así su propia identidad en los aspectos comunes.

Brossa y Madoz se conocieron cuando el poeta ya era muy mayor. Sin embargo tuvieron ocasión de acercar ambas obras y ofrecer sus similitudes para potenciar su fuerza. Glòria Bordons en la introducción del libro Fotopoemario, una publicación donde ambos presentan parte de sus obras en un diálogo, explica que fueron sus propios trabajos los que les llevaron a saber el uno de otro. Madoz conoció la obra de Brossa en la exposición que se realizó en el Centro de Arte Reina Sofía de Madrid y, a su vez, Brossa conoció la obra de Madoz a través de un libro de fotografías que tenía un amigo en su estudio ${ }^{3}$.

Fotopoemario está compuesto por doce fotografías y doce poemas entrelazados unos con otros. Fotografías y poemas que no tienen la función de ilustrar nada, sino de acompañarse mutuamente y ofrecer una lectura distinta gracias a la cercanía.

Así, el poema Succès y la fotografía que le sigue -ambos mostrados al comienzo de este texto-, son un ejemplo de cómo se unen poema y fotografía a lo largo del libro. Cada uno de ellos guarda su propia identidad sin que se vea afectada por la obra que le acompaña, aunque no cabe duda que cada trabajo ejerce una influencia en el otro. Como explico más adelante, ambos juegan en la frontera entre lenguaje y e imagen. Así, las imágenes que surgen de la poesía de Brossa, se ven reforzadas por las ideas que nacen de la fotografía de Madoz. Si Succès es una pequeña pintura de un suceso, la bóveda salpicada de signos musicales es

${ }^{3}$ BROSSA. J, MADOZ. C.: Fotopoemario. Madrid. La Fábrica. 2003. Pág. 7. 
una sugerencia de escritura. En ambas podemos pensar que hablan de lo que sucede por encima de nosotros -a pesar de nosotros-, pero cada una lo hace desde su espacio propio.

Esta experiencia de la creación de libros junto a otros artistas ya la había tenido Brossa anteriormente. Parece como si hubiese comprendido desde muy joven que la colaboración potencia las obras. Miró, Tàpies, Chillida o Perejaume entre otros participaron en colaboraciones donde cada artista presentaba su obra junto a la de Brossa, en estrecha unión pero nunca como ilustraciones una de otra. Por ésta y otras experiencias, una de las características de la biografía de Brossa es su círculo de amistades: artistas y escritores que se impulsaron unos a otros ayudando así a resistir contra la mediocridad que marcaban los tiempos.

Entre Joan Brossa y Chema Madoz hay una diferencia de 39 años. Años además muy decisivos en el panorama cultural, político, territorial, económico, industrial y de toda índole. La obra de Brossa, escrita íntegramente en catalán y destacando en ella su defensa de la cultura catalana, siempre ha estado abierta a las nuevas corrientes europeas que entraban como podían en España. Por poner un ejemplo, su primer libro de poesía, Fogall de sonets ${ }^{4}$, está muy cerca de las prácticas surrealistas que se estaban realizando por aquellos momentos en Fran$\mathrm{cia}^{5}$.

Por otro lado, Chema Madoz nació en plena dictadura franquista en Madrid, pero su obra comenzó a conocerse en los primeros años de la democracia; unos años que comenzaban a despertar con fuerza, pero habían sido tan yermos en todo el ámbito cultural -con sus destacadas excepciones- que no era fácil entrar en el circuito del arte. Sobre todo tratándose de fotografía, a través de la cual era aún más difícil darse a conocer fuera de los ámbitos del periodismo o la publici$\operatorname{dad}^{6}$.

Joan Brossa y Chema Madoz les ha tocado vivir unos años muy determinantes en España, haciendo que esta situación haya marcado sustancialmente sus trabajos; sin embargo, parece que en lugar de verse debilitados, hayan tomado la ocasión como un reto para ayudar a romper con la mediocridad que se impuso durante demasiado tiempo.

\footnotetext{
${ }^{4}$ BROSSA. J.: Fogalls de sonets. Barcelona. Edicions 62. 1985.

5 «En relación a Brossa cabría destacar al citado J.V. Foix, que fue el primero en proporcionar los textos y las revistas a través de los cuales conoció el ambiente artístico europeo. Foix, por su parte, proporcionaba la entrada en Barcelona de las corrientes más polémicas de las vanguardias literarias, inclinándose fundamentalmente por el surrealismo, dando a conocer su pensamiento a través de los textos literarios publicados en la revista L'amic de les arts. (L'amic de les arts. Sitges, dedicado al surrealismo). COLOMER. P. «El universo Brossa». Joan Brossa. Poemas visuales- poemas objeto- instalaciones. Oviedo. Caja Asturias. 1997. Págs. 93-105. Pág. 94.

6 FERNÁNDEZ, N.: «Chema Madoz habla con Alejandro Castellote.» Conversaciones con fotógrafos. Madrid. La Fábrica y Fundación Telefónica. 2003 Págs. 34-38. En la conversación con Alejandro Castellote, Madoz habla de lo duro que le resultó comenzar a mostrar su trabajo, tanto en España como en Francia, en concreto dentro de Les rencontres internationales de la photographie en Arlès.
} 


\section{COLABORACIONES.}

De todos es conocida la afinidad de Brossa por las artes plásticas. Su amistad con diferentes artistas y sus trabajos comunes dan prueba de ello.

Si la colaboración entre dos artistas es una práctica que potencia las obras, Brossa, junto a otros artistas, estuvieron dándose fuerza mutua a lo largo de muchos años, contribuyendo a tejer la sólida red que marcó el arte de la época.

Las circunstancias hicieron que Brossa tuviese la ocasión de conocer artistas tan destacados como Joan Miró, el cual, debido a la gran admiración que el poeta sentía por él, influyó mucho en sus primeros trabajos. Con Miró también tuvo la ocasión de realizar algunos trabajos juntos, como Oda a Joan Miró .

«Brossa recuerda con emoción su primer contacto con Miró en 1941. Sobre él nos cuenta: «... recuerdo que un amigo (Foix) me presentó a Miró. Yo sentía una gran admiración por Miró porque lo veía como el exponente del automatismo que a mí me interesaba. [...] Nos hicimos amigos; sólo el hecho de conocer a Miró para mí ya fue mucho....»8.

Las primeras colaboraciones comenzaron con las revistas Algol -junto a Joan Ponç, Arnau Puig, Jaume Mercader y Francec Boadella,- o Dau al set, fundada con Antoni Tàpies y el primo de éste, Cixart, para pasar más adelante a libros e incluso cine, donde trabajó junto al director Pere Portabella.

«El interés por el surrealismo, la admiración de Brossa por la personalidad y la obra de Joan Miró, las colaboraciones con artistas (Miró, Tàpies, Villèlia, Ponç, Borrell, Perejaume, Amat, Niebla y un largo etcétera) son hitos importantes que han incrementado la atención que el poeta ha dedicado a las artes visuales con repercusiones evidentes en su obra»?

Para explicar mejor cómo se definen las colaboraciones entre estos artistas, tomo el ejemplo de los trabajos realizados junto a Tàpies, como Novel.la o Nocturn Matinal. En Novel.la, hay una serie de litografías de Tàpies «engarzadas»10 a una novela de Brossa. ${ }^{11}$ Cuando ha habido ocasión, Brossa siempre ha queri-

\footnotetext{
7 «Oda a Joan Miró. Suite de poesía visual de 16 poemas en edición de bibliófilo acompañados de 9 litografías de Miró. Ed. La Polígrafa. Barcelona.» COLOMER. P. «Exposiciones, ediciones, publicaciones, estrenos». Joan Brossa. Poemas visuales- poemas objeto- instalaciones. Oviedo. Caja Asturias. 1997. Págs. 107-118. Pág.109.

${ }^{8}$ COLOMER. P. «El universo Brossa». Joan Brossa. Poemas visuales- poemas objeto- instalaciones. Oviedo. Caja Asturias. 1997. Págs. 93-105. Págs. 94-95.

${ }^{9}$ VALLÉS I ROVIRA I.: «El itinerario creativo de Joan Brossa: de la palabra a la imagen». Brossa poemas visuales 1975-1997. Consorcio cultural Goya- Fuentetodos. Zaragoza. 1999. Pp. 48-68. Pág. 63.

${ }^{10}$ Término empleado por el propio Brossa para explicar la relación de las obras en los cuadernos. Recogido en el programa «A fondo» de RTVE. SOLER. J.: «Joan Brossa» A fondo. [DVD]. Madrid. Gran Vía Ediciones. 2005.

${ }^{11}$ El tema de la novela de Brossa sigue una línea documental legal de una persona, desde que nace y se le realiza la partida de nacimiento, hasta que fallece y se realiza un certificado de defunción. Son documentos que forman el rastro de una persona. (ibídem. palabras no textuales).
} 
do subrayar que la relación que hay entre él y los artistas que han trabajado en los diferentes libros es una relación «de igual», colocando una obra al lado de otra, en paralelo, y nunca una ilustrando nada. Este aspecto es muy importante para comprender la manera en la que Brossa quería que se entendiera este tipo de obras, pues en la igualdad se entiende mejor el proceso de potenciar los trabajos que cuando se trata de una ilustración, término que lleva implícito una jerarquía.

Estas colaboraciones son fruto de un entendimiento tanto personal como artístico. Así nació el Fotopoemario y así se entiende, pues ambas obras se complementan de forma muy natural y $\sin$ artificios.

Fotopoemario nació tan sólo unos años antes de la muerte de Brossa, pero a pesar de la edad todavía tuvo fuerzas para crear una pequeña serie de poesías para la publicación ${ }^{12}$.

La estructura del libro coloca en una sola página un poema de Brossa, en la página siguiente su traducción al castellano y en la siguiente una fotografía de Madoz. Así, el lector-espectador va leyendo poemas y mirando fotografías de forma entrelazada, haciendo que una obra enriquezca su sentido con la que le acompaña.

Los poemas que componen Fotopoemario son muy visuales, ya no sólo porque evoquen unas imágenes muy claras como se ha visto en el poema Succès, sino porque la propia estructura es también muy visual, como le ocurre al poema $\mathrm{La}$ cara pública

Tàncat

Per vacances

del.

al.

És un servei de la consellería popular

De cultura catalana.

LA CARA PÚBLICA:

Cerrado por vacaciones

del.

al. ......

Es un servicio de la consejería popular

De cultura catalana. ${ }^{13}$

12 «A pesar de la avanzada edad del poeta y su precario estado de salud, la sugerencia de las fotos del artista madrileño, lo llevó a una creación totalmente paralela, como en los mejores casos de los libros hechos hacía muchos años con artistas de la talla de Joan Miró o Antoni Tàpies entre otros.» BROSSA, J. /MADOZ, CH. Fotopoemario Madrid. La Fábrica. 2003. Pág. 8.

${ }^{13}$ BROSSA, J. MADOZ, CH.: Fotopoemario Madrid. La Fábrica. 2003. Pág. 21, 22. Poema de Joan Brossa. Traducción Carlos Vitale. 


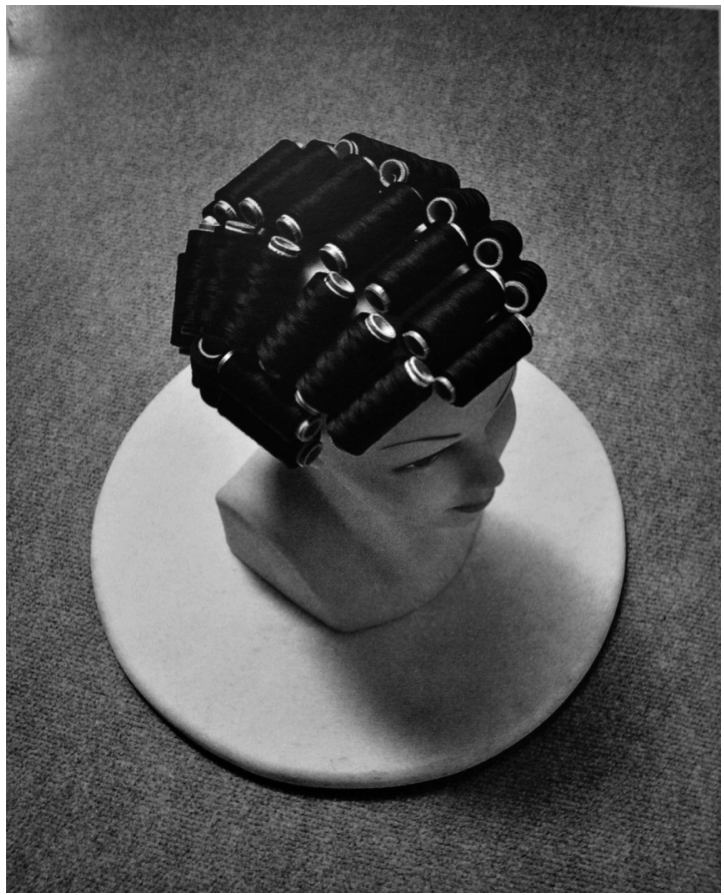

Fig.2. MADOZ.CH.: fotopoemario. Madrid. La Fábrica. 2003. Pág. 25.

Pensando que Brossa recibió una gran influencia del surrealismo francés, no es extraño el recurso que utiliza de introducir el espacio en blanco del papel como un elemento más del poema al modo por ejemplo, de Mallarmé en Un coup de dès jamais n'abolira le hasard'14.

Igualmente, estos poemas se acercan a la esfera de Duchamp, afianzando así la idea de su influencia surrealista. Si Duchamp propuso un agrandamiento del espacio artístico introduciendo elementos que por tradición se encontraban en el extremo opuesto al arte, Brossa en estos doce poemas, recurre a formas del discurso que nunca se hubieran planteado como recursos poéticos, como le sucede al poema La cara pública. Un texto así, encontrado en la puerta de una Consejería, cualquiera que lo lee lo toma por lo que es: un texto que explica el funcionamiento de una oficina. Sin embargo, cuando Brossa lo aparta de la puerta y lo lleva a las páginas de un libro, sigue un procedimiento al estilo de Duchamp: aísla el texto y desplaza su carácter explicativo hacia un carácter simbólico e incluso político, pues sólo en estas páginas el lector tiene la oportunidad de pensar sobre la dimensión de estas palabras y su verdadero alcance; ¿Puede la cultura irse de vacaciones?

${ }^{14}$ MALLARMÉ. S.: Un coup de dès jamais n’abolira le hasard. París. Gallimard. 1987. 


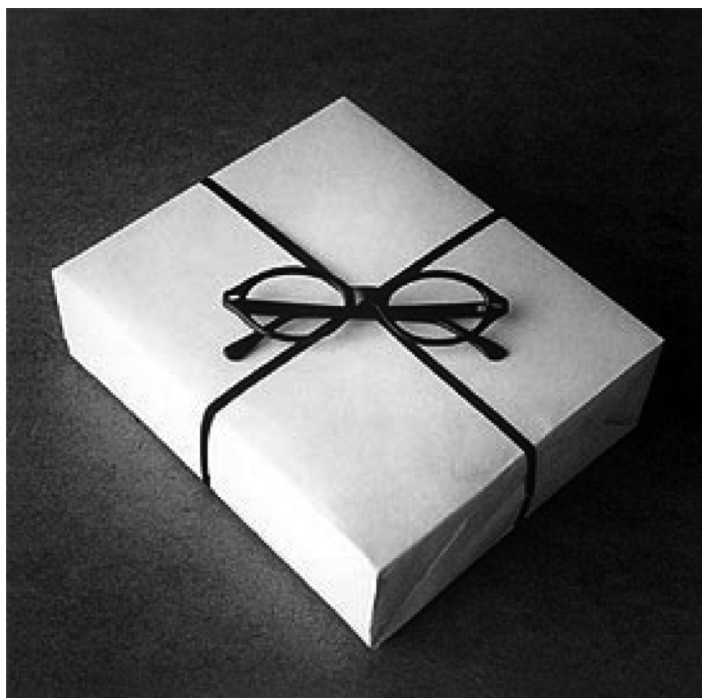

Fig. 3. MADOZ.CH.: fotopoemario. Madrid. La Fábrica. 2003. Pág. 31.

A su vez Chema Madoz, al igual que Brossa, explora el desplazamiento y con él el extrañamiento que ofrece el uso de los objetos. Objetos tan comunes que los conocemos desde antes de nacer, llevando en ellos implícita su manera de utilizarlos. ¿A quién se le ha explicado cómo se utilizan unas gafas? Sin embargo, en el desplazamiento que propone Madoz deja explícito que los objetos pueden ser ellos mismos sin la necesidad de su utilización, rompiendo con ello el binomio objeto-uso.

De este modo, Madoz utiliza la fotografía de manera muy literaria, tomando los recursos que tradicionalmente se emplean en poesía. Ambos rompen así, desde sus herramientas de expresión, con los supuestos de cada una, entrando la palabra de forma natural en el terreno de la imagen y la fotografía en el terreno del poema.

Así, ambos artistas van mostrando su trabajo uno junto al otro, sin que ninguno se imponga al otro, cediéndose el paso a lo largo de todo el Fotopoemario y aumentando la capacidad de transmitir que ambos poseen.

La cercanía de lenguajes que ambos comparten queda, pues, reflejada en parte en esta pequeña obra. No obstante, ambos tienen algunos elementos más que acercan sus trabajos.

\section{LOS TERRENOS COMPARTIDOS ENTRE LA OBRA DE BROSSA Y $M A D O Z$}

Joan Brossa y Chema Madoz tuvieron una relación corta pero intensa y cordial. Cuando ambos conocieron la obra del otro fueron los primeros en comprender que 


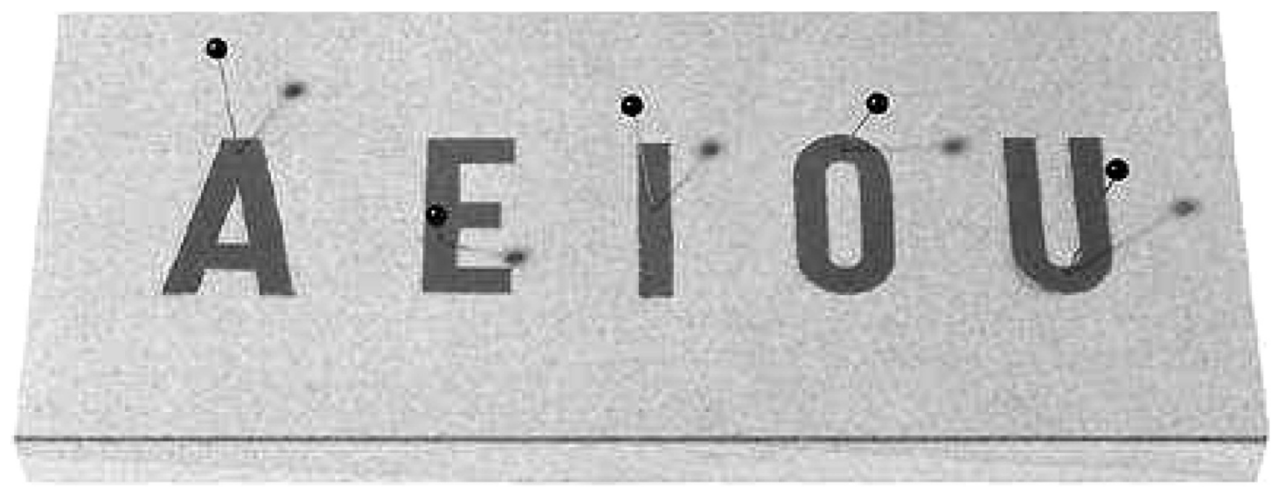

Fig. 4. BROSSA. J.: «insectari (insectario)» La palabra imaginada. Diálogos entre plástica y literatura en el arte español. Segovia. Junta de Castilla y León. 2007. Pág. 84.

entre ellas existía una cercanía que revelaba unas inquietudes comunes en cada uno. Brossa, tras entrar más de lleno en el terreno de la plástica ${ }^{15}$, le interesó especialmente el mundo del objeto. Aunque la palabra no dejaba de tener una presencia protagonista en su obra, ésta tomó una vía diferente cuando se trataba de trabajar en el terreno de la imagen, preocupándose más por el significante como elemento plástico.

Su poesía por lo tanto se amplió de los formatos más tradicionales - aunque nunca fue un poeta tradicional- a formatos más vinculados con la imagen como la poesía visual, los poemas- objeto o las instalaciones en espacios públicos. Este ensanchamiento en el concepto de «poema» le introduce en un campo de investigación muy amplio, donde no solamente experimenta con todo aquello que le parece válido para construir un poema, sino que también lo hace con el propio significado del concepto, poniendo a prueba hasta dónde puede alcanzar su sombra. Cualquier cosa puede ser buena para formar parte de la poesía; incluso él mismo.

Así, en su empeño por hablar sobre la libertad de expresión en cualquier ámbito y forzando a la poesía hacia nuevos terrenos, nos presenta el poema Insectari (Fig. №4). Si no fuera Brossa el que firma este poema-objeto la antítesis no sería tan potente; de esta manera, autor y poema se funden para crear su retórica. La forma de pensar de Brossa, viva y libre como la mariposa se sitúa frente a unas letras «muertas» y expuestas como el trofeo de quien ha atrapado lo inatrapable. Sin embargo todo aquél que cree haber hecho esto no entiende que este gesto es una

15 «A partir de 1963, sus colaboraciones con pintores se hacen cada vez más frecuentes. Su aproximación a la plástica se evidencia, sobretodo, en la poesía escrita. Sin embargo, cuando Brossa colabora con Tàpies en $\mathrm{Pa}$ a la barca, o con Miró [...] sólo intercambia textos literarios. La aparición de poemas visuales en colaboraciones no tendrá lugar hasta 1965, cuando junto con Tàpies edita Novel.la.» COLOMER. P. «El universo Brossa». Joan Brossa. Poemas visuales- poemas objeto- instalaciones. Oviedo. Caja Asturias. 1997. Págs. 93-105. Pág. 98. 


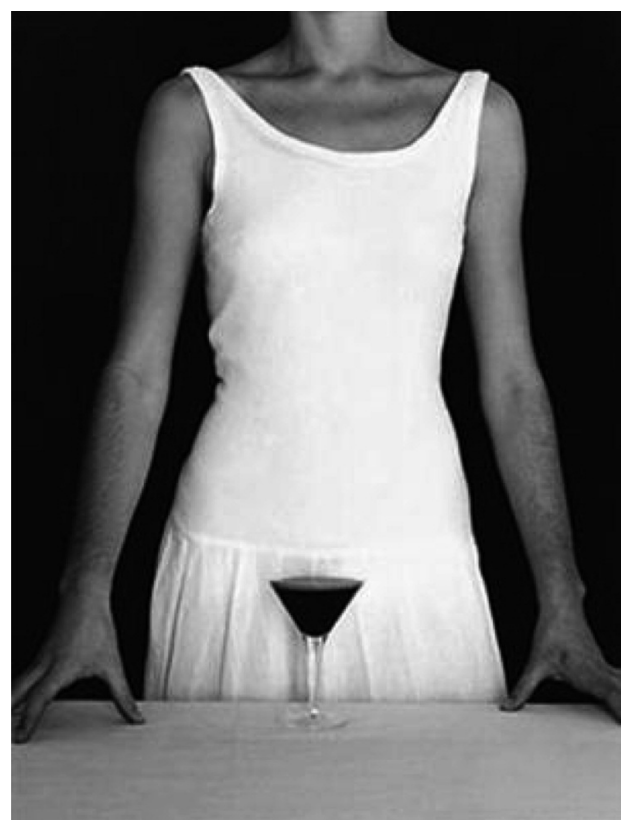

Fig. 5. MADOZ.CH.: Obras maestras. Madrid. La Fábrica. 2009. Pág. 87.

pura ilusión, pues lo esencial de la mariposa o las palabras no es su materia sino su energía.

Con este poema y con tantos otros, Brossa se muestra no solamente como poeta sino como persona, dejando claro que él mismo forma parte de su obra así como su poesía es una parte esencial de su vida.

En la obra de Madoz nos encontramos con que el objeto es su campo de acción casi desde el comienzo. Si bien es cierto que en las primeras fotografías introduce la figura humana, a ésta la trata como un signo o como un recurso poético, potenciando lo anónimo de cada cuerpo y huyendo de todo aquello que desvele una identidad.

Chema Madoz ha comentado que debido a su manera de trabajar, el paso de eliminar la figura humana y centrarse en el objeto fue algo muy natural, pues las personas que posaban para sus fotografías no aportaban más que los objetos: nada de expresividad, ni de emoción. Es decir, como aquello que las diferenciaba de una planta o de un lápiz no surgía, las acabó eliminando de su obra ${ }^{16}$.

El objeto, como le ocurre a Brossa, nunca es representado con un afán de recoger su apariencia física sin más. Como dice Octavio Paz en la cita recogida ${ }^{17}$, el

${ }^{16}$ FERNÁNDEZ, N .: «Chema Madoz habla con Alejandro Castellote.» Conversaciones con fotógrafos. Madrid. La fábrica y Fundación Telefónica. 2003. Págs. 22-23.

17 Ir a la cita no 21. 
objeto se acaba situando a caballo entre él mismo y el signo: ni enteramente objeto ni enteramente signo. El resultado de su fotografía es por lo tanto una construcción de elementos que funcionan como imagen y como signo, pero sin dejar muy claro dónde se encuentra la tradicional división entre significante-significado.

Con esto me refiero a que el concepto de la fotografía en Chema Madoz está muy próximo al concepto de lenguaje, el cual, para expresar un mensaje recurre a una serie de signos colocados bajo una estructura que les da sentido y bajo un contexto que lo sitúa.

Si bien es cierto que Madoz crea una estructura para que los objetos interactúen entre ellos ofreciendo algo parecido a un mensaje, éstos siguen guardando una identidad que no los saca completamente de su sentido inicial. Es decir, aunque unas gafas actúen como lazo que adorna un paquete regalo ${ }^{18}$, su función sigue intacta, creando así el juego entre la función primera y la nueva que se le ha otorgado. Por lo tanto, el desplazamiento provocado por la estructura creada en la imagen no acaba de borrar lo esencial de cada objeto, por lo que nos encontramos ante algo que se recrea en su indefinición.

Por otro lado, en la obra de ambos autores nos encontramos con una preocupación por la idea que sirve de detonante para concebirla y construirla. Así, esta manera de comprender el trabajo los aleja de aquellos procesos más intuitivos o improvisados. Tanto Madoz como Brossa dejan el rastro de un proceso meditado anterior a la ejecución de la obra. Esto no significa que sólo trabajen de manera racional sin dejar paso a las emociones, sino que éstas no llevan el protagonismo en la expresión de sus resultados.

«Para Joan Brossa, la intencionalidad, idea o tema es el desencadenante del proceso creativo. La idea, de hecho, contiene en germen todas las potencialidades de la futura obra, y en su estado mental, consciente (racional) o subconsciente (emocional), equivale a un sistema mental de representación constituido por la selección de imágenes, conceptos o las mismas sensaciones, selección efectuada a instancias de la idea, tema o de la intencionalidad creativa que preside la elaboración de la obra» ${ }^{19}$.

A su vez, Chema Madoz es un artista que «atrapa» el chispazo que le presentan los objetos, trabajando sobre él para darle una forma tangible. La idea primero y la imagen después, ése es el camino. Él mismo cuenta que sin embargo, unas veces ocurre que la idea es atractiva pero su puesta en escena no "cuaja», y otras veces algo que comienza con una débil intuición acaba tomando mucha fuerza cuando pasa a ser una imagen. Por lo tanto, aunque la idea es el detonan-

\footnotetext{
${ }^{18}$ Fig. $n^{0} 3$

${ }^{19}$ VALLES I ROVIRA, I. «Joan Brossa y la problemática del lenguaje conceptual y visual: conceptos de creatividad, del arte y de la historia del arte.» El papel y la función del arte en el siglo XX. Universidad del País Vasco. 1994. P-p. 377-393. Pág. 381.
} 
te de la imagen, el proceso que transforma lo primero en lo segundo es también fundamental; no se puede, pues, separar idea de imagen, pues ambas deben llevarse bien para que nazca la obra. Por lo tanto ¿el problema en la obra de Madoz es la formalización de la idea? Una formalización muy condicionada por la técnica fotográfica diría yo, pues parece que el planteamiento y la puesta en escena son inseparables. Una puesta en escena donde las decisiones técnicas son fundamentales para darle materia al concepto. ${ }^{20} \mathrm{Y}$ dado que no se conoce de él otros procesos de creación que el proceso fotográfico, pienso que si el concepto no está bien resuelto fotográficamente, éste se desecha.

Para Joan Brossa, la formalización de la idea no parece que suponga demasiado problema, pues vista su obra y la cantidad de recursos que ha utilizado, casi se podría decir que primero surge una inquietud que resolver y luego ya se verá cómo se cristaliza.

En el caso concreto de los objetos, Joan Brossa trabaja un nuevo género llamado el poema-objeto ${ }^{21}$, el cual se dice que es el pater familias de este género en España. ${ }^{22}$ El objeto es entonces un elemento que Brossa y Madoz comparten cada uno desde su imaginario e inquietudes. Brossa realizó su primer poema-objeto en 1943, aunque esto no significó que a partir de ese momento se centrara en esta nueva manifestación de la poesía. El poema- objeto, si bien fue un nuevo recurso en su trabajo, siempre convivió con el resto de su obra en su afán por implicarse con la realidad de la manera más completa posible. ${ }^{23}$

En el caso de Madoz, el objeto ocupa el espacio central de su obra desde hace más de dos décadas. Así, el objeto le ofrece una fuente inagotable de recursos que se muestran constantemente en unas imágenes cargadas de ideas y aciertos.

Sin embargo, como he comentado más arriba, el proceso de trabajo que realiza Madoz es muy diferente al de Joan Brossa, aunque el resultado ofrezca simi-

\footnotetext{
20 «En mis imágenes utilizo los menos elementos posibles, y eso también lo he aplicado al equipo». CLAVER. J C. / REPLINGER.M.: Chema Madoz Objetos. [DVD] MNCARS. 2000. También se refiere al uso de la luz, comentando que sólo utiliza luz natural.

21 «En el poema-objeto la poesía no opera únicamente como puente sino también como explosivo. Arrancados de su contexto, los objetos se desvían de sus usos y de su significación. Oscilan entre lo que son y lo que significaron. No son ya objetos y no son enteramente signos. Entonces ¿qué son? Son cosas mudas que hablan. Verlas es oírlas. ¿Qué dicen? Dicen adivinanzas, enigmas. De pronto esos enigmas se entreabren y dejan escapar, como la crisálida a la mariposa, revelaciones instantáneas.» PAZ, Octavio, El arco y la Lira, México 1973. Citado por COMBALÍA, V. «La mirada perturbadora de Joan Brossa». Joan Brossa. Carmen Calvo. España en la XLVII Bienal de Venecia. Editorial Electa. Madrid. 1997. Págs. 89-90.

22 Íbidem. Pág. 89.

23 «La búsqueda de un nuevo código que amplíe el campo de la poesía es, en todo caso, una consecuencia directa del deseo de acercarse a la realidad que siente con fuerza el poeta, un deseo no alcanzado con el cultivo del lenguaje escrito y /o literario que por su carácter abstracto, convencional y polisémico se aleja del contacto directo de la existencia cotidiana». VALLES I ROVIRA, I. «Joan Brossa y la problemática del lenguaje conceptual y visual: conceptos de creatividad, del arte y de la historia del arte.» El papel y la función del arte en el siglo XX. Universidad del País Vasco. 1994. pp. 377-393. Pág. 60.
} 


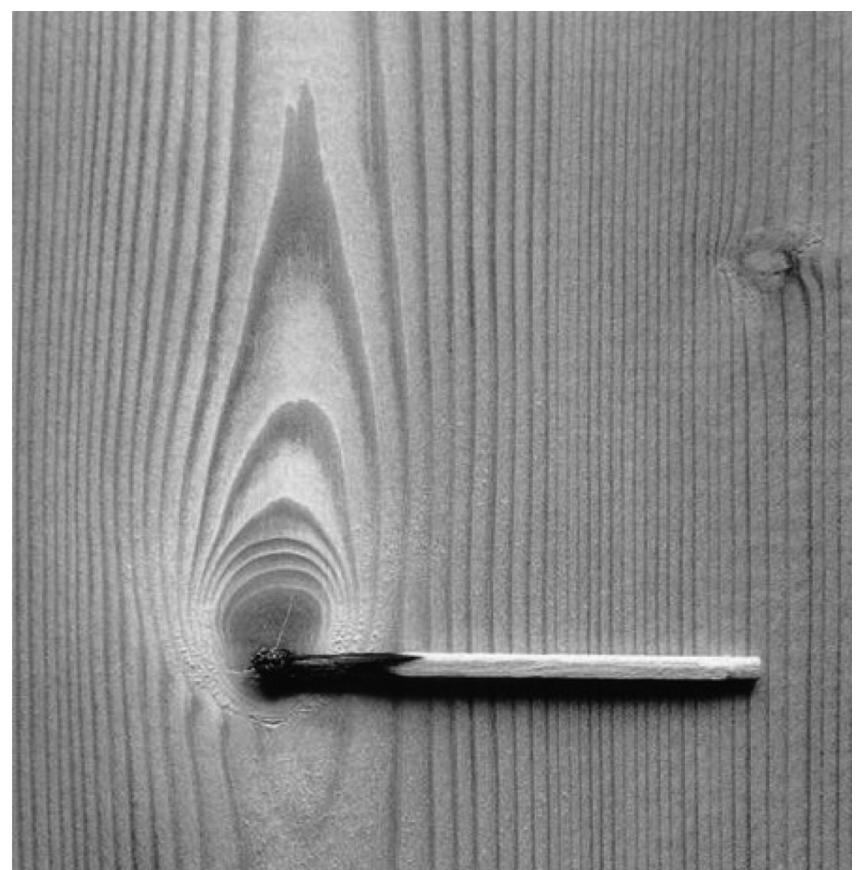

Fig. 6. MADOZ, CH. Objetos 1990-1999.

Madrid. MNCARS. 1999.

Pág.103.

litudes de concepto. Madoz es ante todo fotógrafo, y su obra así lo demuestra. Su lenguaje pasa por la cámara como el de Brossa pasa por las palabras.

Si bien es cierto que los objetos de Madoz son interesantes en sí mismos, (no hay más que entrar en su estudio para ver que muchos de ellos le acompañan en su día a día), también es cierto que no acaban de completarse si no han posado delante del objetivo. De hecho, muchos de los objetos que se pueden mirar en las fotografías ya no existen, pues fueron concebidos exclusivamente para el momento del disparo. Esta forma de incidir en la importancia de este momento único e irrepetible, cercano a lo que se entiende por un acontecimiento real, la encuentro en la fotografía de la figura oㅜ 6 . Si en el siglo XIX La Fotografía nació por un afán de «atrapar» la realidad, esta fotografía es la prueba de que ni por esas la realidad se deja alcanzar. La imagen queda, pero el momento en el que se unieron cerilla y veta de la madera apenas si duró un instante. Madoz no sólo fotografía la cerilla, la veta y su simpática unión, también destapa un aspecto efímero y frágil, pues todos sabemos al ver esta imagen que ya nada queda de ese momento. Entonces, ¿qué percibimos primero, la similitud de la llama o la brevedad del momento?

Por lo tanto, no se trata tanto de presentar un nuevo artefacto como de presentar una nueva realidad: aquélla construida con ayuda de la materia y de la luz. Una realidad que no se contempla sino que se lee, pues entra enteramente en el terreno del lenguaje. 
Algunos objetos empleados por Madoz no son muy distintos de los que utiliza Joan Brossa, dado que en ambos se percibe una intención de utilizarlos como concepto. Los lápices de Brossa o los de Madoz tienen en común una apariencia desnuda, sin artificios, actuando como ellos mismos aunque formen parte de los juegos a los que se someten. Sin embargo, debido precisamente a estos juegos que se traen Brossa o Madoz, cada lápiz o sombrero adquiere el carácter propio que le otorga cada autor, quedando al descubierto su identidad como artistas.

Otros objetos son forzosamente diferentes, pues la experiencia con ellos también lo es. Brossa nació en la segunda década del siglo XX, cuando la industria no estaba ni mucho menos desarrollada en España, aunque Cataluña fuera de las primeras provincias en acogerla. Los objetos de sus poemas son simples e incluso pobres, pero esa simpleza y pobreza no son cualidades sino actitudes, pues en ellos se percibe un posicionamiento muy marcado ante la situación política y social que estaba viviendo. Este posicionamiento influyó de forma decisiva en su obra como no podía ser de otra forma: el 1950 els comunistas catalans erem presents en el propòsit de remarcar la dimensió política de les nostres obres sense abandonar el camí de la renovació. [.... $]^{24}$.

«[...] la publicación de una serie de obras que demuestran el espíritu de rebelión del autor ante una situación - la político-social- cada vez más insostenible. Así, la Antología de poemes de revolta (1943-1978) nos permite vislumbrar un Brossa enfrascado en la lucha para mejorar la sociedad, mientras que en 1950 escribió Des d'un got d'aigua fins al petroli y $U$ no ès ningú» ${ }^{25}$.

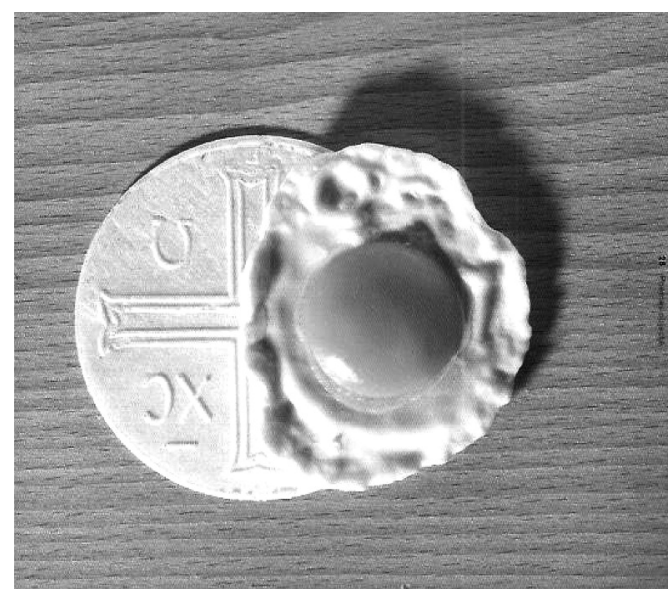

Fig. 7. BROSSA. J. «Eclipsi (eclipse)» Brossa. 1941-1991. Madrid. MNCARS. 1991. Pág. 177.

\footnotetext{
${ }^{24}$ BROSSA.J./TÀPIES. A.: U no ès ningú, Barcelona. Polígrafa S.A. 1979. Pág. 3.

${ }^{25}$ VALLÉS I ROVIRA I.: «El itinerario creativo de Joan Brossa: de la palabra a la imagen». Brossa poemas visuales 1975-1997. Zaragoza. Consorcio cultural Goya- Fuentetodos1999. Pp. 48-68. Pág. 57.
} 


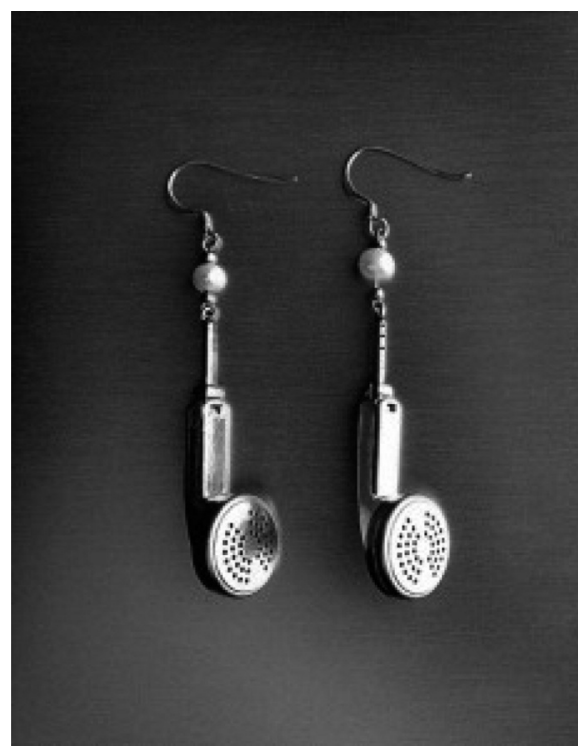

Fig. 8. MADOZ, CH.: Obras maestras. Madrid. La Fábrica. 2009. Pág. 257.

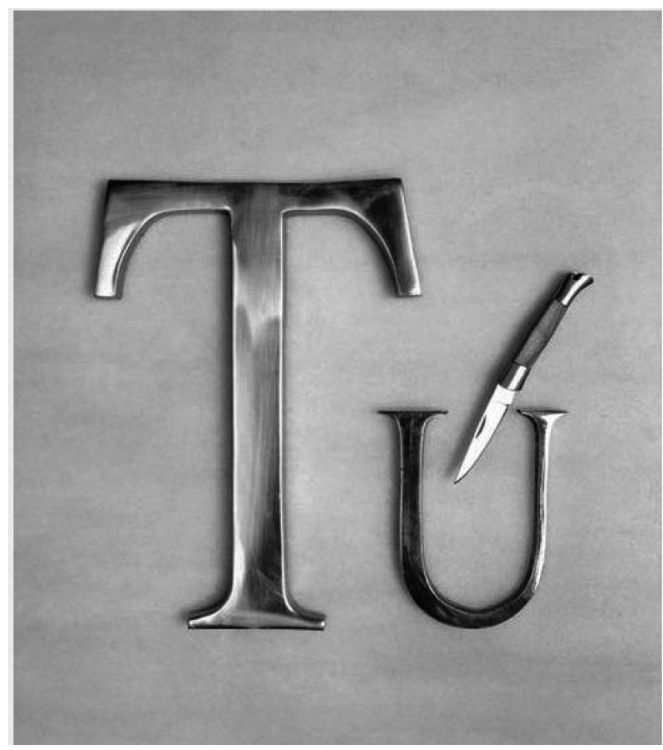

Fig. 9. MADOZ.CH. La palabra imaginada. Diálogos entre plástica y literatura en el arte español. Segovia. Junta de Castilla y León. 2007. Pág. 61.

Brossa tomó el objeto como un elemento para la acción y una oportunidad para la denuncia, tal como hizo con todo el resto de su obra. Como él dijo en alguna ocasión, «si no pudiera escribir, en los momentos de euforia sería guerrillero, en los de pasividad prestidigitador. Ser poeta incluye las dos cosas ${ }^{26}$. Así, La figura $\mathrm{n}^{\circ}$ 7, Eclipsi, es una muestra incendiaria de cómo un poema es un truco de magia donde dos simples objetos se convierten en un arma de fuego poética con sólo unirlos.

Por otro lado, los textos encontrados que giran en torno a la obra de Madoz no expresan de forma explícita un posicionamiento político del artista, sin embargo, no es necesario encontrar frases sobre ello para entender que sus imágenes no son únicamente un despliegue técnico junto a unos hallazgos "con chispa». Si bien en sus fotografías se percibe unos recursos estilísticos que demuestran una preocupación por la exterioridad de la imagen, también es cierto que tras esa primera capa de armonía lumínica y formal nos encontramos mensajes que casi nunca son igual de armónicos.

La fotografía de la figura no 9 es un buen ejemplo de esto que acabo de decir; si bien en ella se ve un uso muy medido de la técnica, también vemos que ésta no va en la única dirección de ofrecer «una buena foto». La brillantez y los remates de

${ }^{26}$ V.V.A.A.: Escrito está poesía experimental en España. Vitoria-Gasteiz. Ediciones La bahía. Pág. 76. 
la tipografía funcionan aquí como parte aglutinadora para potenciar el significado, acercándose a la textura y la forma de la navaja. Igual que las palabras de un texto utilizan una única tipografía para crear unidad, lo mismo ocurre con la palabra TÚ en esta imagen: todos sus elementos se esfuerzan por formar parte de la misma unidad, con todo lo que esto conlleva.

Si hiciera el mismo análisis con la fotografía de la figura $n^{\circ}$ 8, también encontraría que si bien utiliza una técnica muy cuidada, ésta va en una dirección que apunta más allá que la de alcanzar una imagen bella.

Madoz, a diferencia de Brossa, nunca pone títulos a sus imágenes, lo cual significa que dirige menos al espectador hacia su idea, dejando que éste sea enteramente responsable de sus conclusiones cuando las hay. Esta ausencia como pie de foto obliga al espectador a posicionarse frente a la imagen; aunque es cierto que este ejercicio de posicionamiento es necesario ante toda imagen, pues sin él las imágenes no nos hablan ${ }^{27}$, las de Madoz necesitan especialmente un criterio claro, pues de lo contrario sólo encontraríamos en sus fotografías el silencio de unos objetos cotidianos.

Desde la fotografía o desde el poema- objeto, cada uno propone un pensamiento a partir de los objetos. En Brossa estos objetos son tangibles y podríamos tocarlos puesto que están presentados como instalaciones. Esta forma de mostrarlos hace que tomen una entidad más contingente, más del «aquí y el ahora», haciendo que convivamos en el mismo espacio e iluminándonos con la misma luz: no tendríamos más que avanzar la mano para comprobar su tacto e incluso oler su materia.

Los objetos que componen el trabajo de Madoz están casi enteramente definidos en el salto que va de su presentación a su re-presentación. Para ellos el hecho fotográfico es la razón de existir, y sin él no alcanzarían su plenitud. Nacieron para ser fotografiados, aunque a alguno de ellos se le haya otorgado el indulto y sigan presentes en su estudio con la actitud de una estrella de cine cuya imagen representada le precede.

A menudo se le pregunta a Chema Madoz por qué no expone sus objetos, y él contesta que de momento no lo necesita. Si a Joan Brossa alguien le preguntó si pensaba fotografiar sus poemas- objeto como parte del proceso de la obra, seguramente hubiera contestado igualmente que no lo necesitaba, pues cada uno utiliza el lenguaje que mejor considera para acercarse a la realidad, y resulta que cada uno tiene el suyo propio.

\footnotetext{
27 «Las imágenes no nos dicen nada, nos mienten o son oscuras como jeroglíficos mientras uno no se tome la molestia de «leerlas», es decir, de analizarlas, descomponerlas, remontarlas, interpretarlas, distanciarla fuera de los «clichés lingüísticos» que suscitan en tanto que «clichés visuales». DIDI- HUBERMAN, G.: Cuando las imágenes toman posición. Madrid. A. Machado Libros. 2008.
} 
Trabajar con objetos no es nada nuevo, muchos artistas lo hacen desde que Duchamp les abrió el paso al mundo del arte. De hecho están tan ligados al homo faber que somos que acaban por formar parte de todos los ámbitos que nos constituyen. El objeto acaba por lo tanto cobrando una dimensión mucho más extensa que la de simple artefacto.

Tan extendido está el uso del objeto como medio para crear arte que no basta con decir que dos artistas se parecen porque ambos utilizan el objeto como parte de sus obras.

En el caso de Chema Madoz y Joan Brossa, la coincidencia de trabajar con el objeto no se queda solamente en la materia. En ambos se percibe un afán de mostrar un aspecto de la realidad que está oculto si no se mira bien. Para Madoz y para Brossa el objeto es una oportunidad para el juego. Como en la magia, que todo ocurre ante nuestros ojos sin que seamos capaces de ver el truco, ellos juegan con esta dualidad presente-oculto para hablarnos de asuntos que no se quedan en el simple espectáculo. A veces sus trabajos corren el riesgo de no ser entendidos o entendidos solamente de forma parcial, pero esta es la característica de toda buena obra y la que la hace inagotable: ese lugar fuera de todo entendimiento que nunca se podrá alcanzar. 
